\title{
Seed Germination and Their Photon Emission Profile Following Exposure to a Rotating Magnetic Field
}

\author{
Victoria L. Hossack*, Michael A. Persinger, Blake T. Dotta* \\ Behavioural Neuroscience and Biology Programs, Laurentian University, Sudbury, Ontario, Canada \\ Email: *vx_hossack@laurentian.ca, ^bx_dotta@laurentian.ca
}

How to cite this paper: Hossack, V.L., Persinger, M.A. and Dotta, B.T. (2019) Seed Germination and Their Photon Emission Profile Following Exposure to a Rotating Magnetic Field. Open Journal of Biophysics, 9, 254-266.

https://doi.org/10.4236/ojbiphy.2019.94018

Received: July 26, 2019

Accepted: August 24, 2019

Published: August 27, 2019

Copyright $\odot 2019$ by author(s) and Scientific Research Publishing Inc. This work is licensed under the Creative Commons Attribution International License (CC BY 4.0).

http://creativecommons.org/licenses/by/4.0/

\begin{abstract}
A multitude of experiments have applied magnetic fields to plants or seeds and found a variety of different and sometimes contradicting results. A magnetic field generating device called the Chrysalis resonator has been shown to influence the brain activity of human participants, the photon emissions from bacteria, mammalian cell cultures and water. In this experiment sunflower seeds (Helianthus annus) were allowed to begin germination and then exposed to either the field generated by the Chrysalis resonator or a sham condition. Their growth and photon emissions were taken over the next 5 days. It was found that the seeds showed less germination 48 hours after exposure and significantly higher photon emissions when 3 seeds were measured together in a dish, but not if 2 seeds or 1 seed were measured. There were no significant differences in the photon measurements from the water the seeds were germinating in. These results may indicate that the seeds became more sensitive to the presence of neighbouring seeds. The photon emissions results were also significantly impacted by external weather conditions.
\end{abstract}

\section{Keywords}

Seed Germination, Photon, Communication, Magnetic Field

\section{Introduction}

The characteristics of magnetic field treatments previously used to treat plants are highly variable, and so are the results [1] [2]. Some consistent findings seem to be reduced growth when high frequency $(\mathrm{GHz})$ magnetic fields such as from cell phones or Gunn generators (produce fields in the microwave frequencies) 
are used [3]. While the high frequency magnetic fields in [3] are man-made and produce decreases in plant growth, there have been other magnetic fields that have similar frequencies to powerlines and electrical outlets $(50-60 \mathrm{~Hz})$ that have shown positive [4] [5] and negative [6] effects in growth. A review of experiments that investigated the effects of reducing the background intensity of the geomagnetic field (either using a Faraday cage-like device or active shielding) also found there was a trend of reduced growth [7]. One study [8] decreased the intensity of the X-component of the geomagnetic field, and found that these conditions could either increase or decrease plant growth depending on the geomagnetic storms conditions.

Studies that apply low intensity magnetic fields with frequencies that converge on the Schumann frequency seem to increase plant growth measures [9] [10] [11] [12]. For example, one study [11] used a $1500 \mathrm{nT}$ field ( 20 times weaker than the geomagnetic field) at frequencies of 0.1 to $100 \mathrm{~Hz}$ to pretreat seeds, and found that exposure to a $10 \mathrm{~Hz}$ field was the most effective at increasing germination, water absorption, and electrical conductivity of the seed leachates. The changes in the electrical conductivity were associated with a more acidic $\mathrm{pH}$ and could indicate that the magnetic field-treated seeds had an altered ion exchange with their external environment [11]. Increased germination was found with exposure to a $400-500 \mu \mathrm{T}$ field ( 10 times stronger than the geomagnetic field) that was applied at frequencies of 1 to $1000 \mathrm{~Hz}$, with $10 \mathrm{~Hz}$ having the largest increase in germination [9]. Recently, researchers applied a magnetic field of 300 $\mu \mathrm{T}$ ( $\sim 10$ times stronger than the geomagnetic field) at $7.83 \mathrm{~Hz}$ (the Schumann frequency) and found an increase in germination compared to controls [12]. Experiments utilizing static magnetic fields that are in the milliTesla intensity range show a high variability of results with findings of decreased [13] and increased growth [14] [15].

Biological organisms emit photons [16]-[23], including plants [14] [24]-[30]. One study that measured photon emissions from seeds, found that they could manipulate the number of photons by altering the temperature and humidity, factors involved in the onset of germination [30]. They also dissected the seeds and determined that the source of photon emissions was specifically from the inner layer of the seed coat surrounding the seed embryo, indicating that it may be involved in signaling the seed to begin germinating [30]. In addition to communication within the organism, photon emissions have also been demonstrated as a method of communication between organisms [17] [18] [23].

Our lab has been conducting research on a series of devices known as the resonator. These devices have been demonstrated to influence the growth of bacteria [31]. This experiment was designed to start testing this device on a different type of biological organism to see if there were any universal effects of this device or if its effects are specific to bacteria. Magnetic fields are increasing in popularity in everything from agriculture to disease treatment and therefore understanding the width of their effects is important. 


\section{Methods}

\subsection{Seed Germination Preparation}

Sunflowers (Helianthus annus) were obtained from the gardening section of a local department store (subtype, Russian mammoth). For each trial, 108 seeds were split between two solutions of $25 \mathrm{~mL}$ of a $5 \%$ bleach solution, submerged for 5 minutes and then washed with tap water. The seeds were put into $100 \mathrm{~mm}$ petri dishes with $10 \mathrm{~mL}$ of President's Choice spring water for germination, with 18 seeds per dish. In each trial there were three $100 \mathrm{~mm}$ dishes in each condition. Three trials were completed of this experiment.

\subsection{Rotating Magnetic Field Device}

The magnetic field device used in this experiment is known as the Chrysalis resonator. It is one model of many that produces a magnetic field around $110 \mathrm{~Hz}$. In this model the exact peak frequency of the magnetic field was $113 \mathrm{~Hz}$. The magnetic field has a strength of approximately 0.75 Gauss, or $75 \mu \mathrm{T}$. A description of a similar model of this device has been previously published [31] and can also be found in the patent (Canadian Patent No. CA 2631215). Briefly, the magnetic field is generated by cylinders that rotate within the device at about 3000 - 4000 rotations per minute when the device is on. The cylinders inside the device are arranged in a circle and contain puck magnets, these rotating puck magnets are responsible for generating the magnetic field.

\subsection{Procedure}

After the seeds were placed into their dishes, they were placed directly on the Chrysalis resonator for 1 hour to either be exposed to the field or to the sham condition (field OFF but with the fan running). Both conditions were complete on the same day with an hour between exposures. When not being exposed and during germination, the seeds were placed on flat surfaces in the dark. Starting 24 hours after exposure, daily measurements were taken for five days to determine if each seed had begun to germinate and to measure the length of the root/stem that had emerged from the shell. Statistical analysis of the length measurements were complete only on the seeds that had begun germination.

After taking growth measurements, photon measurements were taken on a photomultiplier tube (PMT). The PMT was model DM0089C, which is most sensitive to photons of wavelengths between 280 to $630 \mathrm{~nm}$. For preparation, 6 seeds were picked from each condition that were within a range of seedling length measurements that had been taken that day (Table 1). These were then put into three $35 \mathrm{~mm}$ dishes; in the first dish there was one seed, in the second dish there were two seeds and in the third dish there were three seeds. Each of these dishes contained $0.5 \mathrm{~mL}$ of fresh spring water, this was to reduce the amount of stress that may have been occurring by measuring these seeds. Additionally, there were $35 \mathrm{~mm}$ dishes measured that contained $1 \mathrm{~mL}$ of spring water from the dishes of germinating seeds. 
Table 1. Approximate range of root/stem lengths of seeds that were chosen from each condition to be used for photon measurements.

\begin{tabular}{cc}
\hline Day of Measurement & Range of seedling length (in millimetres) \\
\hline 1 & $0-1$ \\
2 & $1-2$ \\
3 & $2-7$ \\
4 & $9-30$ \\
5 & $30-80$ \\
\hline
\end{tabular}

The PMT was housed in a black-painted wooden box that was covered in black towels. The seed dishes were placed on top of the PMT aperture. Samples were measured three times for one minute intervals at a sampling rate of $50 \mathrm{~Hz}$. For statistical analysis, the average of the second and third recording was used. The first recording was not used to reduce the effect of light pollution. An example of a recording can be seen in Figure 1, from this the mean of all the points was computed as well as the standard deviation of all the points.

\section{Results}

\subsection{Germination}

Seeds were germinated in $100 \mathrm{~mm}$ petri dishes, with 18 seeds in one dish. The percent number of seeds in each dish that germinated were calculated for each day for both the magnetic field exposure and sham condition. The average was taken of the three dishes in each condition. There was a significant interaction between day of measure and the field condition $\left[\mathrm{F}(4,16)=4.51, \mathrm{p}=0.013 ; p \eta^{2}=\right.$ 0.53; Figure 2]. There was a significant decrease in the proportion of seeds which germinated for the magnetic field condition compared to the sham condition. Paired t-tests for each condition showed the interaction comes from difference in slope between day 1 and day 2 for the two conditions (Figure 2), evident in the disparity between the t-statistics (Table 2). This indicates that the effect on germination rate wasn't evident until the day 2 measurement, which was taken 48 hours after exposure.

Length of seedling was then measured for the seeds that had germinated. There was no significant difference between the field exposed of sham exposed seedlings $[F(4,16)=0.45, p=0.770$; Figure 3$]$.

\subsection{Photon-Seed}

Initial results indicated no significant effects, however there was a large variability between the average number of photons between the different replicate of experiments $\left[\mathrm{F}(2,17)=15.2, \mathrm{p}<0.001, \Omega^{2}=19.3 \%\right.$; Figure 4], as well as large differences in the standard deviation of the number of photons $[\mathrm{F}(2,17)=27.0$, $\mathrm{p}<0.001, \Omega^{2}=24.8 \%$; Figure 4$]$. In both variables, Tukey's post hoc test determined that the second replicate was significantly higher than the first and third replicate $(\mathrm{p}<0.05)$. 


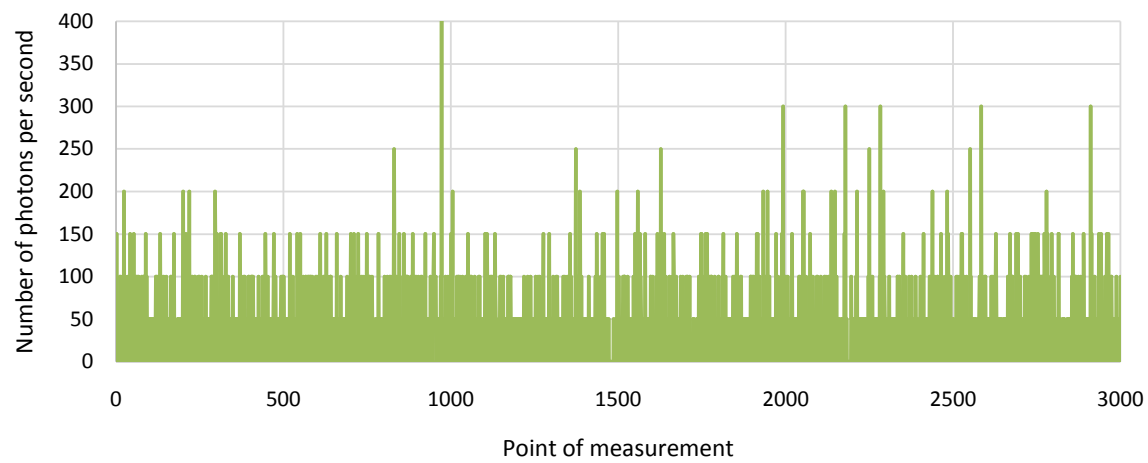

Figure 1. Example of 1 minute recording of seeds on photomultiplier tube. One measurement was taken every 20 milliseconds (sampling rate of $50 \mathrm{~Hz}$ ).

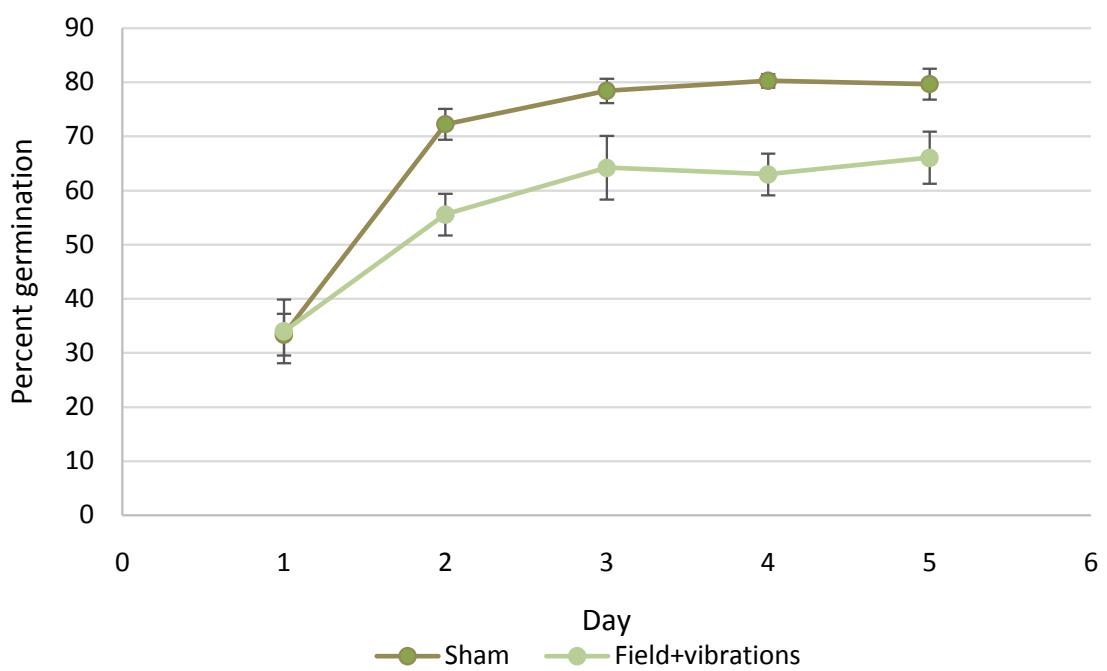

Figure 2. The percent number of seeds that germinated over 5 days in the dark, resting in spring water. Seeds begun germination at Day 0 and were subsequently exposed to one of the conditions. Error bars represent SEM.

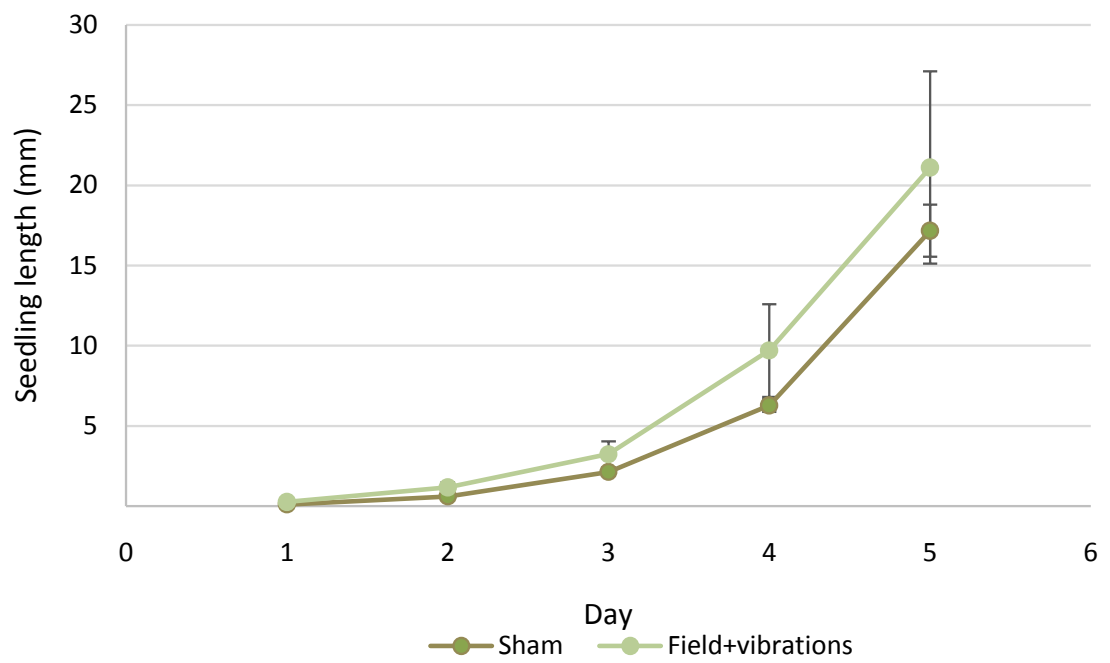

Figure 3. The length of seedling over the 5 days of germination in the dark. Seeds begun germination at Day 0 and were subsequently exposed to one of the conditions. Error bars represent SEM. 


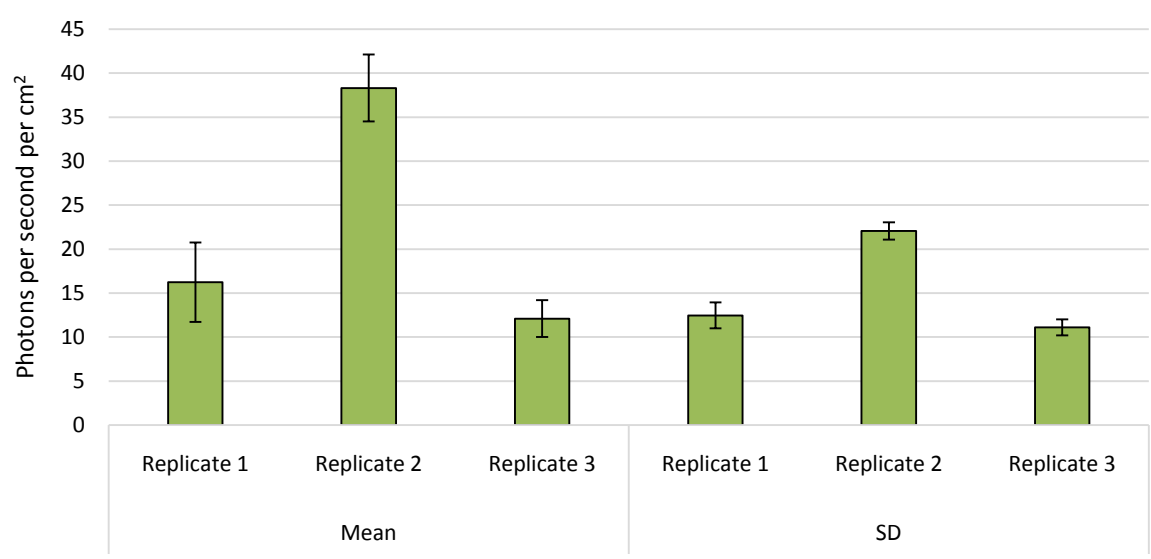

Figure 4. Difference across in mean and standard deviation (SD) photons in the three different replicates. Error bars represent the SEM.

Table 2. Paired t-tests between the 5 days of measurement for the different magnetic field conditions. Values represent the t-statistic which had 2 degrees of freedom.

\begin{tabular}{ccccc}
\hline & Day 1 to 2 & Day 2 to 3 & Day 3 to 4 & Day 4 to 5 \\
\hline Sham & $18.2^{*}$ & 1.25 & 1.73 & 0.378 \\
Field & $9.71^{*}$ & 2.14 & 0.555 & 2.50 \\
\hline
\end{tabular}

${ }^{*}=\mathrm{p}<0.05$.

Due to this large variability between replicates, two statistical methods were used for further analysis. The first was entering weather variables into the dataset, to see if controlling for any of these removed the variability. Second, within-subjects z-scores for each replicate were used as well to confirm any results found with the weather variables.

Weather variables included in the dataset were the daily and hourly average of temperature, relative humidity and AP index. Also included were the hour of day (in Eastern Standard Time) the measurements were taken and the day of year the replicate began. Using a series of multivariate analysis of covariances (MANCOVAs) it was determined that most of the significant covariates were from the between subjects analysis (between the three replications) and not the within subjects analyses (within each single replication) (Table 3). Temperature and humidity explained the most variance when using the values for the hour of photon measurement, whereas the AP index explained the most variance when using the daily average values (Table 3 ). A regression analysis was used with all of the weather variables and the mean number of photons. The only variable that entered as a predictor was the daily average AP index $[\mathrm{F}(1,17)=32.4, \mathrm{p} \leq 0.001$, $\mathrm{r}^{2}=0.648$; Table 4].

The residuals from this analysis were saved as a new variable and analyzed in a two-way ANOVA, finding a significant main effect for the number of seeds $[\mathrm{F}(2$, $17)=9.40, p=0.003]$ and a significant two way interaction between the number of seeds and resonator condition $[\mathrm{F}(2,17)=4.28, \mathrm{p}=0.040$; Figure $5(\mathrm{~b})]$. Tukey's post-hoc test determined this was being driven by the 3 seeds group in the 
Table 3. F-values from multivariate analysis of covariance with weather variables from the hour of photon measurement or the daily average. Included are the effect sizes, represented as partial eta ${ }^{2}\left(p \eta^{2}\right)$.

\begin{tabular}{|c|c|c|c|c|c|}
\hline \multirow[b]{2}{*}{ Covariate } & \multirow[b]{2}{*}{ Statistic } & \multicolumn{2}{|c|}{ Mean photons per second per $\mathrm{cm}^{2}$} & \multicolumn{2}{|c|}{ SD photons per second per $\mathrm{cm}^{2}$} \\
\hline & & $\begin{array}{l}\text { Between- } \\
\text { subjects }\end{array}$ & $\begin{array}{l}\text { Within- } \\
\text { subjects }\end{array}$ & $\begin{array}{c}\text { Between- } \\
\text { subjects }\end{array}$ & $\begin{array}{l}\text { Within- } \\
\text { subjects }\end{array}$ \\
\hline \multirow{2}{*}{$\begin{array}{c}\text { Temperature of } \\
\text { hour }\end{array}$} & F- statistic & $46.3^{* *}$ & 0.84 & $80.7^{* *}$ & 2.83 \\
\hline & $p \eta^{2}$ & 0.81 & 0.018 & 0.88 & 0.057 \\
\hline \multirow{2}{*}{$\begin{array}{l}\text { Temperature, } \\
\text { daily average }\end{array}$} & F- statistic & 0.20 & 0.00 & 0.12 & 1.33 \\
\hline & $p \eta^{2}$ & 0.018 & 0.0001 & 0.011 & 0.028 \\
\hline \multirow{2}{*}{ Humidity of hour } & F- statistic & $47.6^{* *}$ & 1.87 & $83.7^{* *}$ & $4.60^{*}$ \\
\hline & $p \eta^{2}$ & 0.81 & 0.038 & 0.88 & 0.089 \\
\hline \multirow{2}{*}{$\begin{array}{l}\text { Humidity, daily } \\
\text { average }\end{array}$} & F- statistic & 4.48 & 1.00 & $5.64^{*}$ & 0.02 \\
\hline & $p \eta^{2}$ & 0.29 & 0.021 & 0.34 & 0.0005 \\
\hline \multirow{2}{*}{ Ap index of hour } & F- statistic & 4.31 & $11.6^{*}$ & 4.11 & $10.8^{*}$ \\
\hline & $p \eta^{2}$ & 0.28 & 0.20 & 0.27 & 0.19 \\
\hline \multirow{2}{*}{$\begin{array}{l}\text { Ap index, daily } \\
\text { average }\end{array}$} & F- statistic & $79.7^{* *}$ & $4.93^{*}$ & $168.4^{* *}$ & 3.81 \\
\hline & $p \eta^{2}$ & 0.88 & 0.095 & 0.94 & 0.075 \\
\hline \multirow{2}{*}{$\begin{array}{c}\text { Hour of } \\
\text { measurement }\end{array}$} & F- statistic & $30.1^{* *}$ & 3.23 & $35.2^{* *}$ & 3.82 \\
\hline & $p \eta^{2}$ & 0.73 & 0.064 & 0.76 & 0.075 \\
\hline \multirow{2}{*}{ Day of year } & F- statistic & 0.66 & \multirow{2}{*}{ Cannot compute } & 0.53 & \multirow{2}{*}{ Cannot compute } \\
\hline & $p \eta^{2}$ & 0.057 & & 0.046 & \\
\hline
\end{tabular}

${ }^{\star} \mathrm{p}<0.05 ;{ }^{* *} \mathrm{p}<0.001$.

Table 4. Regression statistics of the daily AP index predicting the mean photons per second per $\mathrm{cm}^{2}$ in germinating seedlings.

\begin{tabular}{cccccc}
\hline Variable & Regression & $\mathrm{r}^{2}$ & B & Std Err of B & Beta \\
\hline Daily AP & 0.82 & 0.65 & 6.53 & 1.15 & 0.818 \\
Constant & & & -20.5 & 7.77 & \\
\hline
\end{tabular}

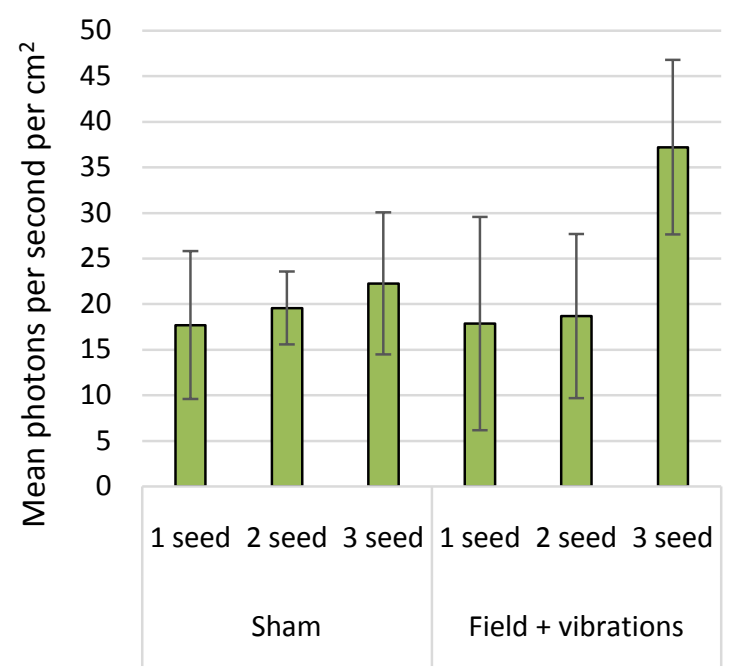

(a) 


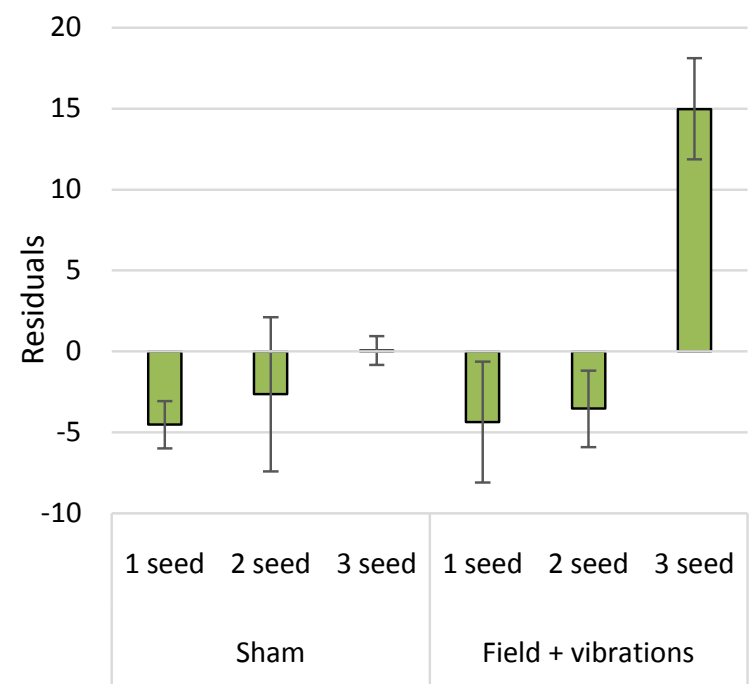

(b)

Figure 5. Mean photon emissions per second per $\mathrm{cm}^{2}$ (assumed diameter of $2.5 \mathrm{~cm}$ for PMT aperture) across the different conditions in a resonator experiment. (a) Original values. (b) Residuals after counting for daily average AP index. Error bars represent SEM.

resonator condition being significantly higher than all other groups $(\mathrm{p}<0.05)$. When an analysis was carried out on the SD of photons, the same main effect for number of seeds $[F(2,17)=7.47, p=0.008]$ and interaction $[F(2,17)=12.0, p=$ 0.001] were found.

Another analysis was then carried out, using within subject z-scores, to see if this would show the same result found above. For this analysis the dataset had to be re-organized. The measurements were averaged over the 5 days into one value and the within-subject component became the number of seeds that were measured and the within-subject $\mathrm{z}$-scores were computed. When a MANOVA was used on the mean number of photons, the effect for number of seeds was still present $[\mathrm{F}(2,8)=5.58, \mathrm{p}=0.030]$, where paired $\mathrm{t}$-tests showed that the 3 seed group was significantly greater than the 1 seed group $(\mathrm{p}<0.05)$; but the there was no longer an interaction with resonator condition $[\mathrm{F}(2,8)=1.25, \mathrm{p}=$ 0.336]. When this same analysis was used with the standard deviation of photons, there was no longer a significant main effect of number of seeds $[F(2,8)=$ $3.51, \mathrm{p}=0.080$ ] but the interaction between number of seeds and resonator condition was significant $[\mathrm{F}(2,8)=4.67, \mathrm{p}=0.045$; Figure 6]. Paired t-tests showed that none of the groups were significantly different in the Sham condition $(\mathrm{p}>$ $0.05)$ but that in the Field + vibrations condition, the 3 seed was group was significantly greater than the 2 seed and the 1 seed group $(\mathrm{p}<0.05)$. These are the same differences found between groups as was found in the residual analysis for the standard deviation of photon recordings.

\subsection{Photon-Water}

There were no differences between the sham and field condition in the photon emissions measured from the water the seeds had been germinating in $(p>$ 
0.05). Similar to the seeds, the mean AP index for the day of measurement was a significant predictor of mean photons (Table 5). A similar relationship was found with the SD of photons recorded. When residuals were used in an ANOVA there was no significant effect between conditions for the mean $[F(1,5)$ $=0.481, \mathrm{p}=0.526]$ or SD of photons $[\mathrm{F}(1,5)=0.768, \mathrm{p}=0.430]$.

\section{Discussion}

Exposure to the dynamic field of the Chrysalis resonator (and its vibrations) caused approximately a $15 \%$ decrease in the number of seeds that germinated. This appeared in the measurements 48 hours after exposure, while there was no difference in germination 24 hours after exposure. Delayed effects of magnetic field exposure on germination have been previously reported [14] [15]. In a recent study involving seed germination and magnetic fields [15], authors found greatest differences between the magnetic field and sham groups at 96 hours after exposure. Decreased germination is an effect previously found with high frequency man-made fields [3] or environments that reduced the background intensity of the Earth's static magnetic field [7]. Is it possible that these two broad categories of magnetic field treatments are reducing a developing seeds coherence or connection with the Earth's magnetic field? The phenomenon of this type of coherence has already been demonstrated in humans [32] [33] [34], where

Table 5. Regression statistics of the daily AP index predicting the mean photons per second per $\mathrm{cm}^{2}$ in spring water seeds were germinating in.

\begin{tabular}{cccccc}
\hline Variable & Regression & $\mathrm{r}^{2}$ & $\mathrm{~B}$ & Std Err of B & Beta \\
\hline Daily AP & 0.97 & 0.94 & 0.802 & 0.094 & 0.974 \\
Constant & & & -3.48 & 0.637 & \\
\hline
\end{tabular}

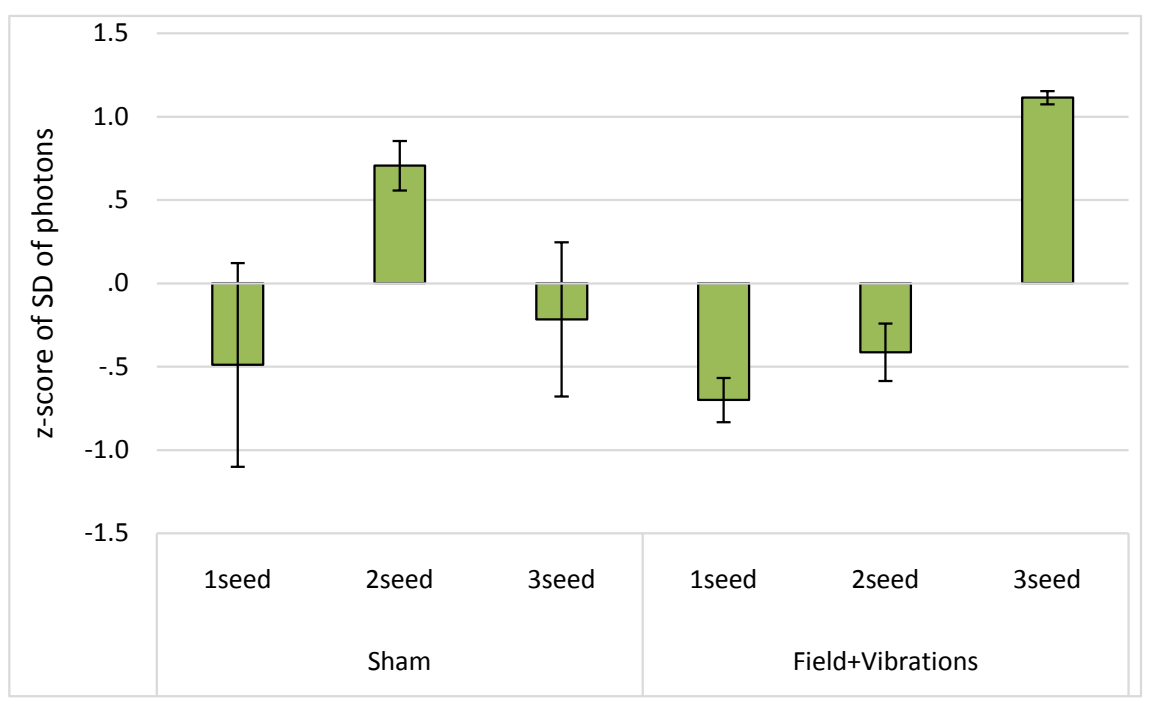

Figure 6. Z-scores of the standard deviation of recording of photon emissions per second per $\mathrm{cm}^{2}$ (assumed diameter of $2.5 \mathrm{~cm}$ for PMT aperture) between the number of seeds measured each replicate. Error bars represent SEM. 
the patterns of electrical activity in the brain correlated with the resonance frequencies of the Earth's magnetic field.

The interaction in photon emissions with number of seeds was evaluated with two different statistical techniques. When using residuals that had controlled for weather variables, the interaction was significant both in the mean photons and standard deviation of photon emissions over the measurement period. However, when using the within subject $\mathrm{z}$-score methods, only the standard deviation interaction remained significant. This indicates that this variable demonstrated the greatest change from exposure to the dynamic condition of the Chrysalis resonator and that the changes in SD would be seen to a lesser extent in the mean values.

Photon communication in biological organisms has been demonstrated many times [17] [18]. For example, it has been found that germinating radish seeds that had been exposed to gamma irradiation could influence the germination rate of other radish seeds that had never been exposed (Kuzin \& Surbenova, 1995 in [35]). Indicating a potential for seed to seed communication through photon emission; when the seed germination rate was altered, these seeds may have been influenced by nearby seeds' through biophoton emission. Biophoton signalling has been previously implicated in the start of germination [30], in this experiment, the resonator may have altered the biophoton signalling of the seeds and as a result interfered with their germination.

In the present experiment, we found altered biophoton emission, but only when three germinating seeds were measured together, and not when one or two seeds were measured. There are several phenomena that could explain this result. The first is signal to noise ratio, where all of the seeds had altered biophoton emission, but three seeds were needed for the PMT to be able to detect the difference between conditions. Another explanation for the results is that the increased photon emissions of the three seeds measured together was the result of a stress reaction in the seeds due to overcrowding. It has been previously demonstrated that changes in population density of biological organisms can alter their biophoton emission [16] and also influence the growth of organisms nearby [18] [23]. This could imply that the resonator induced the germinating seeds

to be hyper sensitive to the presence of other seeds nearby. This may also explain the decrease in germination that was found, in that it was a response to increased population density, which could also explain why the decrease in germination was found 48 hours after the beginning of germination and not 24 hours after. There is an increased likelihood that the plants would be able to sense the presence of surrounding seeds at that time, either by their individual biophoton emission, physical contact or seed leachates.

\section{Conclusion}

This experiment demonstrated that the Chrysalis resonator can affect the germination of sunflower seeds as well as their biophoton emissions. Further re- 
search needs to be conducted to find the mechanisms by which magnetic fields affect plants. Literature reviews [1] [2] have found highly variable responses of plants to magnetic fields. Here we demonstrated the importance of considering the influence environmental conditions may have on results.

\section{Conflicts of Interest}

The authors declare no conflicts of interest regarding the publication of this paper.

\section{References}

[1] Maffei, M.E. (2014) Magnetic Field Effects on Plant Growth, Development, and Evolution. Frontiers in Plant Science, 5, 445. https://doi.org/10.3389/fpls.2014.00445

[2] Nyakane, N.E., Markus, E.D. and Sedibe, M.M. (2019) The Effects of Magnetic Fields on Plants Growth: A Comprehensive Review. International Journal of Food Engineering, 5, 79-87.

[3] Vian, A., Davies, E., Gendraud, M. and Bonnet, P. (2016) Plant Responses to High Frequency Electromagnetic Fields. BioMed Research International, 2016, Article ID: 1830262 . https://doi.org/10.1155/2016/1830262

[4] Naz, A., Jamil, Y., ulHaq, Z., Iqbal, M., Ahmad, M.R., Ashraf, M.I. and Ahmad, R. (2012) Enhancement in the Germination, Growth and Yield of Okra (Abelmoschus esculentus) Using Pre-Sowing Magnetic Treatment of Seeds. Indian Journal of Biochemistry and Biophysics, 49, 211-214.

[5] Aleman, E.I., Mbogholi, A., Boix, Y.F., Gonzalez-Ohnedo, J. and Chalfun, A. (2014) Effects of EMFs on Some Biological Parameters in Coffee Plants (Coffea arabica L.) Obtained by in Vitro Propagation. Polish Journal of Environmental Studies, 23, 95-101.

[6] Mroczek-Zdyrska, M., Kornarzynski, K., Pietruszewski, S. and Gagos, M. (2016) The Effects of Low-Frequency Magnetic Field Exposure on the Growth and Biochemical Parameters in Lupin (Lupinus angustifolius L.). Plant Biosystems, 151, 504-511. https://doi.org/10.1080/11263504.2016.1186123

[7] Belyavskaya, N.A. (2004) Biological Effects Due to Weak Magnetic Field on Plants. Advances in Space Research, 34, 1566-1574.

https://doi.org/10.1016/j.asr.2004.01.021

[8] Rakosy-Tican, L., Aurori, C. and Morariu, V. (2005) Influence of Near Null Magnetic Field on in Vitro Growth of Potato and Wild Solanum Species. Bioelectromagnetics, 26, 548-557. https://doi.org/10.1002/bem.20134

[9] Namba, K., Sasao, A. and Shibusawa, S. (1995) Effect of Magnetic Field on Germination and Plant Growth. Acta Horticulturae, 399, 143-148. https://doi.org/10.17660/ActaHortic.1995.399.15

[10] Betti, L., Trebbi, G., Fregola, F., Zurla, M., Mesirca, P., Brizzi, M. and Borghini, F. (2011) Weak Static and Extremely Low Frequency Magnetic Fields Affect in Vitro Pollen Germination. The Scientific World Journal, 11, 875-890. https://doi.org/10.1100/tsw.2011.83

[11] Radhakrishnan, R. and Kumari, B.D. (2013) Influence of Pulsed Magnetic Field on Soybean (Glycine max L.) Seed Germination, Seedling Growth and Soil Microbial Population. Indian Journal of Biochemistry and Biophysics, 50, 312-317. 
[12] Huang, P., Tang, J., Feng, C., Cheng, P. and Jang, L. (2018) Influences of Extremely Low Frequency Electromagnetic Fields on Germination and Early Growth of Mung Beans. IEEE International Conference on Consumer Electronics- Taiwan, Taichung, 1-2. https://doi.org/10.1109/ICCE-China.2018.8448809

[13] Vashisth, A. and Nagarajan, S. (2009) Effect on Germination and Early Growth Characteristics in Sunflower (Helianthus annus) Seeds Exposed to Static Magnetic Field. Journal of Plant Physiology, 167, 149-156.

https://doi.org/10.1016/j.jplph.2009.08.011

[14] Ćirković, S., Bačić, J., Paunović, N., Popović, T.B., Trbovich, A.M., Romčević, N. and Ristić-Djurović, J.L. (2017) Influence of $340 \mathrm{mT}$ Static Magnetic Field on Germination Potential and Mid-Infrared Spectrum of Wheat. Bioelectromagnetics, 38, 533-540. https://doi.org/10.1002/bem.22057

[15] Podleśna, A., Bojarszczuk, J. and Podleśny, J. (2019) Effects of Pre-Sowing Magnetic Field Treatment on Some Biochemical and Physiological Processes in Faba Bean ( Vicia faba L. spp. Minor). Journal of Plant Growth Regulation, 1-8. https://doi.org/10.1007/s00344-019-09920-1

[16] Galle, M., Neurohr, R., Altmann, G., Popp, F.A. and Nagl, W. (1991) Biophoton Emission from Daphnia Magna: A Possible Factor in the Self-Regulation of Swarming. Experientia, 47, 457-460. https://doi.org/10.1007/BF01959943

[17] Albrecht-Buehler, G. (2005) A Long-Range Attraction between Aggregating 3T3 Cells Mediated by Near-Infrared Light Scattering. Journal of Cell Biology, 114, 493-502. https://doi.org/10.1083/jcb.114.3.493

[18] Fels, D. (2009) Cellular Communication through Light. PLoS ONE, 4, e5086. https://doi.org/10.1371/journal.pone.0005086

[19] Dotta, B.T., Saroka, K.S. and Persinger, M.A. (2012) Increased Photon Emission from the Head While Imagining Light in the Dark Is Correlated with Changes in Electroencephalographic Power: Support for Bókkon's Biophoton Hypothesis. Neuroscience Letters, 513, 151-154. https://doi.org/10.1016/j.neulet.2012.02.021

[20] Persinger, M.A., Dotta, B.T., Karbowski, L.M. and Murugan, N.J. (2015) Inverse Relationship between Photon Flux Densities and Nanotesla Magnetic Fields over Cell Aggregates: Quantitative Evidence for Energetic Conservation. FEBS Open Bio, 5, 413-418. https://doi.org/10.1016/j.fob.2015.04.015

[21] Dotta, B.T., Murugan, N.J., Karbowski, L.M., Lafrenie, R.M. and Persinger, M.A. (2014) Shifting Wavelengths of Ultraweak Photon Emissions from Dying Melanoma Cells: Their Chemical Enhancement and Blocking Are Predicted by Cosic's Theory of Resonant Recognition Model for Macromolecules. Naturwissenschaften, 101, 87-94. https://doi.org/10.1007/s00114-013-1133-3

[22] Dotta, B.T., Karbowski, L.M., Murugan, N.J., Vares, D.A.E. and Persinger, M.A. (2016) Ultra-Weak Photon Emissions Differentiate Malignant Cells from Non-Malignant Cells in Vitro. Archives in Cancer Research, 4, 2. https://doi.org/10.21767/2254-6081.100085

[23] Fels, D. (2017) Endogenous Physical Regulation of Population Density in the Freshwater Protozoan Paramecium caudatum. Scientific Reports, 7, Article No. 13800. https://doi.org/10.1038/s41598-017-14231-0

[24] Bernard, B.S. and William, A. (1951) Light Production by Green Plants. The Journal of General Physiology, 20, 809-820. https://doi.org/10.1085/jgp.34.6.809

[25] Yan, Y. (2006) Biophoton Emission and Delayed Luminescence of Plants. In: Biophotonics-Optics Science and Engineering for the 21 th Century, Springer, New York, 195-204. https://doi.org/10.1007/0-387-24996-6_15 
[26] Gallep, C.M. and dos Santos, S.R. (2007) Photon-Counts during Germination of Wheat (Triticum aestivum) in Wastewater Sediment Solutions Correlated with Seedling Growth. Seed Science and Technology, 35, 607-614. https://doi.org/10.15258/sst.2007.35.3.08

[27] Sun, Y., Wang, C. and Dai, J. (2010) Biophotons as Neural Communication Signals Demonstrated by in Situ Biophoton Autography. Photochemical \& PhotobiologicalSciences, 9, 315-322. https://doi.org/10.1039/b9pp00125e

[28] Moraes, T.A., Barlow, P.W., Klingelé, E. and Gallep, C.M. (2012) Spontaneous Ultra-Weak Light Emissions from Wheat Seedlings Are Rhythmic and Synchronized with the Time Profile of the Local Gravimetric Tide. Die Naturwissenschaften, 99, 465-472. https://doi.org/10.1007/s00114-012-0921-5

[29] Gallep, C.M., Moraes, T.A., Cervinková, K., Cifra, M., Katsumata, M. and Barlow, P.W. (2014) Lunisolar Tidal Synchronism with Biophoton Emission during Intercontinental Wheat-Seedling Germination Tests. Plant Signaling \& Behavior, 9, e28671. https://doi.org/10.4161/psb.28671

[30] Footitt, S., Palleschi, S., Fazio, E., Palomba, R., Finch-Savage, W.E. and Silvestroni, L. (2016) Ultraweak Photon Emission from the Seed Coat in Response to Temperature and Humidity-A Potential Mechanism for Environmental Signal Transduction in the Soil Seed Bank. Photochemistry and Photobiology, 92, 678-687.

https://doi.org/10.1111/php.12616

[31] Tessaro, L.W.E., Murugan, N.J. and Persinger, M.A. (2015) Bacterial Growth Rates Are Influenced by Cellular Characteristics of Individual Species When Immersed in Electromagnetic Fields. Microbiological Research, 172, 26-33. https://doi.org/10.1016/j.micres.2014.12.008

[32] Pobachenko, S.V., Kolesnik, A.G., Borodin, A.S. and Kalyuzhin, V.V. (2006) The Contingency of Parameters of Human Encephalograms and Schumann Resonance Electromagnetic Fields Revealed in Monitoring Studies. Biophysics, 51, 480-483. https://doi.org/10.1134/S0006350906030225

[33] Persinger, M.A. (2014) Schumann Resonance Frequencies Found within Quantitative Electroencephalographic Activity: Implications for Earth-Brain Interactions. International Letters of Chemistry, Physics and Astronomy, 30, 24-32. https://doi.org/10.18052/www.scipress.com/ILCPA.30.24

[34] Saroka, K.S., Vares, D.E. and Persinger, M.A. (2016) Similar Spectral Power Densities within the Schumann Resonance and a Large Population of Quantitative Electroencephalographic Profiles: Supportive Evidence for Koenig and Pobachenko. PLoS ONE, 11, e0146595. https://doi.org/10.1371/journal.pone.0146595

[35] Cifra, M., Fields, J.Z. and Farhadi, A. (2011) Electromagnetic Cellular Interactions. Progress in Biophysics and Molecular Biology, 105, 223-246.

https://doi.org/10.1016/j.pbiomolbio.2010.07.003 